\title{
Status of RNB Facilities in North America
}

\author{
Jerry A. Nolen \\ Physics Division, Argonne National Laboratory \\ Argonne, IL 60439, U.S.A.

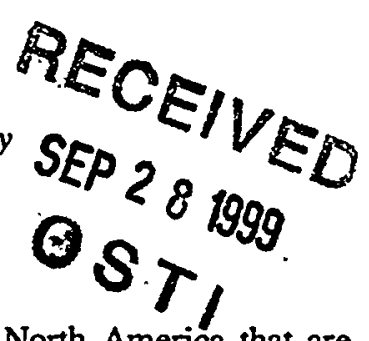

Abstract. This paper presents the status of accelerator facilities in North America that are involved in research using radioactive nuclear beams (RNB), including existing and operating facilities, ones currently under construction or undergoing major upgrades, and ones being planned or proposed for the future. Existing RNB facilities are located at TRIUMF (TISOL) in Vancouver, B.C., the Holifield Radioactive Ion Beam Facility (HRIBF) at Oak Ridge National Laboratory, the Argonne Tandem Linear Accelerator System (ATLAS) at Argonne National Laboratory, the National Superconducting Cyclotron Laboratory (NSCL) at Michigan State University, the Nuclear Structure Laboratory at The University of Notre Dame, the 88" Cyclotron at Lawrence Berkeley National Laboratory, and the Cyclotron Institute at Texas A\&M University. Currently, there are two major RNB facility upgrades in progress in North America, one at TRIUMF, the ISAC project, and one at NSCL, the Intensity Upgrade project. For the future, the U. S. Nuclear Science Advisory Committee has given high priority for an advanced RNB facility of the ISOL type. Concepts for such a facility, currently being developed at Argonne National Laboratory and Oak Ridge National Laboratory, are presented. Plans are also being developed in Canada at TRIUMF for a major upgrade of the ISAC facility.

\section{INTRODUCTION}

There are four qualitatively different types of radioactive beam facility: isotopeseparator-on-line (ISOL), batch, in-flight, and fragmentation. ISOL facilities have existed at reactors and accelerators for over 30 years, but methods to accelerate the separated isotopes for nuclear physics research with energetic radioactive beams have only been developed recently. At ISOL facilities the production targets and ion sources are closely coupled so that isotopes are produced, extracted, ionized, separated, and delivered for research on time scales of milliseconds to seconds. In batch-mode facilities the production is physically separated from the ionization and acceleration so that isotopes must have half-lives typically in the minutes to hours range. The in-flight and fragmentation modes use nuclear reactions of energetic primary beams to produce secondary radioactive species that are delivered for research without stopping, on time scales of microseconds. In this paper the in-flight mode is distinguished from the fragmentation mode. The in-flight mode refers to the production of secondary beams via direct reactions with inverse in the beam line. Typical reactions are inverse $(p, n)$ or $(d, n)$ using plastic foil or hydrogen gas cell targets. The primary heavy-ion beams are 


\section{DISCLAIMER}

This report was prepared as an account of work sponsored by an agency of the United States Government. Neither the United States Government nor any agency thereof, nor any of their employees, make any warranty, express or implied, or assumes any legal liability or responsibility for the accuracy, completeness, or usefulness of any information, apparatus, product, or process disclosed, or represents that its use would not infringe privately owned rights. Reference herein to any specific commercial product, process, or service by trade name, trademark, manufacturer, or otherwise does not necessarily constitute or imply its endorsement, recommendation, or favoring by the United States Government or any agency thereof. The views and opinions of authors expressed herein do not necessarily state or reflect those of the United States Government or any agency thereof. 


\section{DISCLAIMER}

Portions of this document may be illegible in electronic image products. Images are produced from the best available original document. 
typically at energies somewhat above the Coulomb barrier. The fragmentation mode is similar except the primary beam energies are typically $100 \mathrm{MeV}$ per nucleon or higher and the reaction is via an abrasion/ablation mechanism rather than a simple transfer or charge-exchange.

\section{EXISTING FACILITIES}

There are seven nuclear physics laboratories in North America, which currently do research with radioactive beams. They are listed briefly in the Table 1 below along with an indication of the production mechanisms used at each. They are separately discussed in separate sub-sections below, sorted according to the production mechanisms used.

TABLE 1. Summary of Existing Facilities

\begin{tabular}{ll}
\hline Location and name & Type \\
\hline TRIUMF/TISOL & ISOL (not accelerated) \\
ORNL/HRIBF & ISOL (accelerated) \\
LBNL/88"/BEARS & Batch \\
ANL/ATLAS & Batch \& In-flight \\
UND/TWINSOL (UND/UofM) & In-flight \\
TAMU/K500-MARS & In-flight \\
MSU/NSCL/K1200 & Fragmentation \\
\hline
\end{tabular}

\section{Current ISOL Facilities}

There are two active ISOL facilities in North America, one at TRIUMF in Vancouver, BC, and one at Oak Ridge National Laboratory in Tennessee.

\section{TRIUMF/TISOL}

The TISOL facility (1) at TRIUMF is a traditional ISOL facility, where the radionuclides are mass separated at ion source energies of $60 \mathrm{keV}$, but not post accelerated. TISOL occupies one of several beam lines from the TRIUMF $500 \mathrm{MeV}$ proton cyclotron and uses up to 1.5 microamperes of primary beam current. Typical isotopes produced and used recently in research include ${ }^{9} \mathrm{C},{ }^{16} \mathrm{~N},{ }^{17} \mathrm{Ne}$, and ${ }^{37} \mathrm{~K}$, with intensities up to about $10 \%$ s. Beta-decay studies related to nuclear astrophysics and fundamental symmetry studies in atom traps (TRINAT) are being pursued.

\section{ORNL/HRIBF}

The Holifield Radioactive Ion Beam Facility (2) at Oak Ridge was recently completed and is currently in the process of developing radioactive beams for research. Radionuclides are produced using beams such as $\mathrm{p}, \mathrm{d}$, or $\alpha$ 's from the ORIC cyclotron 
at energies of 50 to $100 \mathrm{MeV}$ and with currents of 10-20 microamperes. The production target/ion source complex produces negative ions for post acceleration by a $25 \mathrm{MV}$ Tandem accelerator. Beams of ${ }^{69,70}$ As have been developed and delivered to targets at intensities on the order of $10^{5} / \mathrm{s}$, and beams such as ${ }^{17} \mathrm{~F}$ and ${ }^{56} \mathrm{Ni}$ are currently being developed with expected intensities of $10^{5}-10^{8} / \mathrm{s}$. Experimental apparatus includes the Daresbury Recoil Separator (DRS) and the Recoil Mass Separator (RMS) for nuclear. astrophysics and nuclear structure research.

\section{Current "Batch-Mode" Facilities}

The superconducting heavy ion linac ATLAS at Argonne has been doing research with accelerated radioactive beams for three years, using both the batch mode and inflight production mechanisms; they are described separately in this sub-section and the next one below. A group at the LBNL 88" cyclotron is currently developing a batchmode radioactive beam capability described below in this sub-section.

\section{ANL/ATLAS}

In 1995 a ${ }^{18} \mathrm{~F}\left(\mathrm{~T}_{1 / 2}=110 \mathrm{~min}\right.$.) beam was developed and used for nuclear astrophysics measurements at ATLAS. The radionuclide was produced and prepared for the ion source at the University of Wisconsin medical cyclotron and flown to Argonne where ${ }^{18} \mathrm{~F}(\mathrm{p}, \alpha)$ cross section excitation functions were measured (3). More recently, a ${ }^{56} \mathrm{Ni}$ beam was developed and used to measure spectroscopic factors via the $(\mathrm{d}, \mathrm{p})$ reaction in inverse kinematics (4). The ${ }^{56} \mathrm{Ni}\left(T_{1 / 2}=6\right.$ days) was produced at the $50 \mathrm{MeV}$ proton linac of the ANL pulsed neutron source (IPNS) and transferred to the ion source of the Tandem at ATLAS for ionization and acceleration. Beam intensities on target were from $3 \times 10^{6} / \mathrm{s}$ at $0.6 \mathrm{MeV} / \mathrm{u}$ for ${ }^{18} \mathrm{~F}$ to $3 \times 10^{4} / \mathrm{s}$ at $5 \mathrm{MeV} / \mathrm{u}$ for ${ }^{56} \mathrm{Ni}$. The experimental apparatus used at ATLAS included the split-pole magnetic spectrograph in the gasfilled mode and the Fragment Mass Analyzer (FMA) in conjunction with a large area silicon detector array near the target.

\section{LBNL/BEARS}

A project called Berkeley Experiments with Accelerated Radioactive Species (BEARS) has been initiated at the LBNL 88" cyclotron (5). The plan is to produce radioactive isotopes such as ${ }^{11} \mathrm{C},{ }^{13} \mathrm{~N}$, and ${ }^{14} \mathrm{O}$ at the LBNL medical cyclotron that is located 300 meters from the $88^{\prime \prime}$ cyclotron. The activity will be carried through a tube via a carrier gas from the medical cyclotron to the $88^{\prime \prime}$ cyclotron. Initial tests with activity created at the $88^{\prime \prime}$ cyclotron have demonstrated that ${ }^{11} \mathrm{C}$ and ${ }^{14} \mathrm{O}$ can be separated from the carrier gas in a liquid nitrogen trap and subsequently delivered slowly into the ECR ion source. Ionization and transport efficiencies of over $3 \%$ of the trapped " $\mathrm{C}$ into the $4+$ charge state were measured after the ion source analyzing magnet (6). Once the two cyclotrons are coupled via the transfer line, accelerated 
beams in the $1-20 \mathrm{MeV} / \mathrm{u}$ energy range with intensities $\sim 10^{4}-10^{8} / \mathrm{s}$ are envisioned. The $8 \pi$-detector array, large area silicon detectors, and the new Berkeley Gas-filled Separator (BGS) are available for research.

\section{Current In-Flight-Production Facilities}

There are three nuclear physics laboratories in North America that are currently doing research with radioactive beams produced via direct reactions in inverse kinematics. Their facilities and activities are summarized below.

\section{Notre Dame/University of Michigan}

For several years a University of Notre Dame and University of Michigan collaboration has been doing research using superconducting magnetic solenoids with large solid angle to capture and refocus radionuclides produced via reactions in the beam line (7). Their current project is based on a pair of superconducting solenoids known as TwinSol (8). The results of first experiments with TwinSol using beams of ${ }^{6} \mathrm{He}$ and ${ }^{8} \mathrm{Li}$ are reported in paper $\mathrm{G} 3$ of this conference (9).

\section{ANLATLAS}

An in-flight production system has been developed at ATLAS during the past two years. The system consists of gas cells with thin Havar windows operating at about 600 Torr of $\mathrm{H}_{2}$ or $\mathrm{D}_{2}$. Inverse $(\mathrm{p}, \mathrm{n})$ or $(\mathrm{d}, \mathrm{n})$ reactions are induced by primary heavy ion beams with intensities of roughly 250 particle nanoamperes. The reaction products are collected and focussed by a superconducting solenoid. A superconducting resonator following the solenoid is used to debunch the time structure of the secondary beam to reduce its energy-spread (10). Excitation functions of the cross section for the fusion of ${ }^{17} \mathrm{~F}+{ }^{208} \mathrm{~Pb}$ have been measured (11) at beam energies of $87-100 \mathrm{MeV}$ with beam intensities of about $3 \times 10^{6} / \mathrm{s}$ on target.

\section{Texas A\&M/MARS}

Groups at the Texas A\&M Cyclotron Institute have been using primary heavy ion beams from the $\mathrm{K} 500$ superconducting cyclotron to initiate reactions in gas targets in the beam line. Radioactive ${ }^{7} \mathrm{Be}$ beams have been used to the $\left({ }^{7} \mathrm{Be},{ }^{8} \mathrm{~B}\right)$ reaction on ${ }^{10} \mathrm{~B}$ and ${ }^{14} \mathrm{~N}$ to determine parameters relevant to the ${ }^{7} \mathrm{Be}(\mathrm{p}, \gamma)$ capture reaction rate (12). The experiments used the recoil mass separator, MARS, to achieve a $99.5 \%$ pure ${ }^{7} \mathrm{Be}$ beam at a rate of $10^{5} / \mathrm{s}$ at the focal plane, where the secondary reaction targets were located. Other research involves the use of radioactive beams to study the isospin dependence of nuclear reactions. 


\section{Current Fragmentation Facility}

The only fragmentation facility in North America is at the National Superconducting Cyclotron Laboratory (NSCL) at Michigan State University.

\section{Michigan State/NSCL}

The NSCL K1200 superconducting cyclotron (13) produces primary beams of heavy ions in the 100 to $200 \mathrm{MeV}$ per nucleon energy range. Energetic radioactive beams produced via the fragmentation mechanism have been used for nuclear physics research at the NSCL for about 10 years. The primary beam, with currents up to approximately 100 particle-nanoamperes, interacts with a target at the front of a Projectile Fragment Separator, the $A 1200(14,15)$. Studies of reaction mechanisms, nuclear structure, and nuclear astrophysics are carried out using the A1200 itself or downstream in other apparatus. The instruments available include magnetic spectrographs (the old $\$ 320$ or the new S800), recoil separators (the RPMS), large-acceptance charged particle and neutron detector arrays, the University of Michigan superconducting solenoid (BIGSOL), and general-purpose scattering chambers. A measurement using the $\mathbf{S 8 0 0}$ and a radioactive ${ }^{8} \mathrm{~B}$ beam was done recently $(16,17)$.

\section{FACILITIES UNDER CONSTRUCTION}

\begin{tabular}{lll} 
TABLE 2. Facilities with Upgrades Currently in Progress \\
\hline Location and name & Type & Construction status \\
\hline TRIUMF/SAC & ISOL & Commissioning in '99-'00 \\
NSCL/K5000K1200 & Fragmentation & Commissioning in '00-'01 \\
\hline
\end{tabular}

\section{TRIUMF/ISAC}

The construction of ISAC (Isotope Separation and Acceleration) at TRIUMF is well underway $(18,19)$. The new facility involves adding a new beam line from the TRIUMF cyclotron to deliver $500 \mathrm{MeV}$ protons with currents up to $100 \mu \mathrm{A}$ to a new target/ion source complex. Radioactive ions are mass analyzed and transported to the RNB accelerator. The accelerator comprises an 8-m long RFQ and an IH-type drifttube linac. The accelerator runs $\mathrm{CW}$ and can accept ions with $\mathrm{m} / \mathrm{q}$ up to 30 . The first half of the RFQ has been assembled and tested successfully with stable beams, $\mathrm{N}^{+}$and $\mathrm{N}_{2}{ }^{+}$. It operated $\mathrm{CW}$ at the required voltage and the energy-gain and acceptance efficiency agreed with design calculations (19). The output energy of the completed accelerator will be continuously variable from $150 \mathrm{keV} / \mathrm{u}$ up to $1.5 \mathrm{MeV} / \mathrm{u}$. The construction of a recoil-mass separator, DRAGON, optimized for measuring capturereaction cross sections has begun. A windowless gas target apparatus to be used for $(p, \gamma)$ and $(\alpha, \gamma)$ measurements is nearing completion. 


\section{Michigan State/K500 $\otimes K 1200$}

A major project involving the coupling of the $\mathrm{K} 500$ and $\mathrm{K} 1200$ superconducting cyclotrons at the NSCL is underway (20). It also involves replacing the present A1200 beam analysis system by an improved A1900 beam analysis system which will have more bending power and a higher capture efficiency to allow preparation of very neutron rich secondary beams. Large gains in radioactive beam intensity, often by two to three orders of magnitude, and significant gains in maximum energy for very heavy beams will be achieved. Primary beam intensities of up to 1 particle microampere at energies of $200 \mathrm{MeV} / \mathrm{u}$ for light, $\mathrm{N}=\mathrm{Z}$, ions will be available. For the heaviest beams, such as ${ }^{238} \mathrm{U}$, the intensities and energies will be approximately $10^{9} / \mathrm{s}$ and $100 \mathrm{MeV} / \mathrm{u}$, respectively. The project is scheduled for completion in the year 2000 .

\section{PROPOSALS FOR NEW FACILITIES OR FACILITY UPGRADES}

In North America there are proposals being developed for ISOL-type facilities in Canada and the United States. A proposal to increase the radioactive beam energy and mass range at ISAC (ISAC2) is being developed at TRIUMF. In the U. S., the Nuclear Science Advisory Committee has given high priority for an advanced RNB facility of the ISOL type. Concepts for such a facility, based on addressing the scientific goals spelled out in a recent white paper (21), are currently being developed at Argonne National Laboratory and Oak Ridge National Laboratory, as indicated in Table 3 below. Either facility would provide instrumentation for research with RNB over a broad mass range and at the various energies appropriate to address the physics delineated in the white paper.

TABLE 3. Proposals for New or Upgraded Radioactive Beam Facilities in North America

\begin{tabular}{ll}
\hline Facility proposals & Time scale \\
\hline TRIUMF/ISAC2 & Next 5-year plan \\
U.S. DOE Advanced ISOL Facility & Begin construction FY 2003 \\
\hline & \\
\hline Possible DOE sites & Facility concepts \\
\hline Argonne: & Multi-beam driver + ATLAS \\
Oak Ridge, option 1: & Spallation neutron source + Post Accelerator \\
Oak Ridge, option 2: & HRIBF facility upgrade \\
\hline
\end{tabular}

\section{TRIUMF/ISAC2}

The ISAC2 proposal currently being developed at TRIUMF is to greatly extend the range of the radioactive beams available for research by increasing the maximum energy available to about $6.5 \mathrm{MeV} / \mathrm{u}$ and the mass capability up to roughly $A=150$ (22). For masses above 30 the $R F Q$ requires higher charge states $(\mathrm{m} / \mathrm{q} \leq 30)$, which would be accomplished either with ECR ion sources or some type of charge-state multiplier. A new drift-tube linac for the high-energy end would be either a room temperature $\mathrm{IH}$ type or a superconducting linac based on short, independently phased resonators. A major building addition would provide space for new experimental apparatus. 


\section{ANL Concept}

The Physics Division at Argonne National Laboratory is developing a concept for an advanced ISOL-type radioactive beam facility based on ATLAS $(23,24)$. The ANL concept features a multi-beam driver and a radioactive beam accelerator with an injector capable of accelerating very heavy ions from 1+ ISOL-type ion sources. Preliminary work is currently in progress to design a $100-\mathrm{kW}$-beam-power, multi-beam driver based on a 200-MV CW superconducting linac (25). The low $\mathrm{q} / \mathrm{m}$ RNB injector is based on the development of a 12-MHz CW RFQ. A full-scale prototype of this RFQ has been operated successfully at the voltage required to accelerate mass $132 / 1+$ ions (26). This prototype will be tested with ${ }^{132} \mathrm{Xe}$ beam in the near future. The multi-beam driver concept gives the facility the flexibility to select the type and energy of primary beam appropriate for optimal production of specific radionuclides. Driver beams available from the 200-MV linac include protons and deuterons at any energy up to $200 \mathrm{MeV}$, secondary neutron beams (27), and heavy ions at energies up to $100 \mathrm{MeV} / \mathrm{u}$. Proton beam energies above $200 \mathrm{MeV}$ could be made available in the future by using the 200MV CW driver as the injector for an isochronous cyclotron or higher energy superconducting linac booster. With the present ATLAS linac serving as the heart of the RNB accelerator very high quality radioactive beams over a broad mass range at energies up to $15 \mathrm{MeV} / \mathrm{u}$ would be available for research

\section{ORNL Concepts}

Two options for an advanced ISOL facility are being considered at Oak Ridge (2). One option is based on using a fraction of the $1-\mathrm{GeV}$ proton beam from the Spallation Neutron Source (SNS) that is currently planned for construction at ORNL. About 100 $\mu \mathrm{A}$ of the SNS proton beam would be diverted to a new ISOL-type RNB facility. The second option is a major upgrade of the present HRIBF. A new high power driver linac would replace the present ORIC cyclotron and a booster linac would follow the $25 \mathrm{MV}$ Tandem to provide RNB over a broader mass range and at higher energies.

\section{LINKS TO RELATED WEB SITES}

There are many sites on the World Wide Web with figures and more detailed descriptions of the material summarized in this summary paper. A few are listed in Table 4 below.

TABLE 4. Web Sites Related to Radioactive Beam Facilities in North America

\begin{tabular}{ll}
\hline Location and name & Web Site \\
\hline TRIUMF/TISOL/ISAC & www.triumf.ca/isac/lothar/isac.html \\
ORNL/HRIBF & www.phy.ornl.gov/hribf/hribf.html \\
LBNL/88"/BEARS & www-nsd.lbl.gov/88 docs/whatsnew.html \\
ANL/ATLAS & www.phy.anl.gov/ \\
UND-UofM /TWINSOL & www.physics.lsa.umich.edu/winsol/ \\
TAMU/K500-MARS & wwwcyc.tamu.edu/ \\
MSU/NSCL & www.nscl.msu.edu/facility/home.html \\
Columbus White Paper & www.er.dec.gov/production/henn/isolpaper.pdf \\
\hline
\end{tabular}




\section{REFERENCES}

1. Domsky, M., et al., "Nucl. Instr. Meth. B70 125 (1992).

2. Alton, G. D., and Beene, J. R., J. Phys. G: Nucl. Part. Phys. 24 1347-1359 (1998).

3. Rehm, K. E., et al., Phys. Rev. C52 R460 (1995).

4. Rehm, K. E., et al., Phys. Rev. Lett. 80 676-679 (1998).

5. Powell, J., et al., "BEARS: Radioactive Ion Beams at LBNL," paper PG12, ENAM98.

6. Xie, Z.-Q., private communication.

7. Becchetti, F. D., and Kolata, J. J., "Low-Energy Radioactive-Beam Experiments Using the UM-UND Solenoid RNB Apparatus at the UND Tandem: Past, Present, and Future," Proceedings of the $14^{\text {th }}$ International Conference on the Application of Accelerators in Research and Industry, Denton, Texas, USA, November 1996, AIP conference proceedings No. 392, 369-375 (1997).

8. Lee, M. Y., et al., "TwinSol: A Dual Superconducting Solenoid System for Low-Energy Radioactive Nuclear Beam Research," ibid., 397-400.

9. Kolata, J. J., "First Results From the TwinSol RNB Facility," paper G3, ENAM98.

10. Pardo, R. C., et al., "Enhanced Transport and Control of In-Beam Produced Radioactive ${ }^{17} \mathrm{~F}$," Proceedings of the XIX Intern. Linac Conf., Chicago, IL, August 23-28, 1998, to be published.

11. Rehm, K. E., et al., Phys. Rev. Lett., to be published.

12. Tribble, R. E., et al., "Determination of the ${ }^{7} \mathrm{Be}(\mathrm{p}, \gamma)^{8} \mathrm{~B}$ rate, $\mathrm{S}_{17}(0)$," paper F7, ENAM98.

13. Nolen, J. A., et al., "Commissioning Experience with the NSCL K1200 Superconducting Cyclotron," Proceedings of the $12^{\text {th }}$ Intermational Conference on Cyclotrons and Their Applications, Berlin, May 8-12, 1989, World Scientific, 5-8 (1991).

14. Sherrill, B.M., et al., Nucl. Instr. and Meth., B56/57 1106 (1991).

15. Sherrill, B.M., et al., "Initial Operating Experience with the A1200 Fragment Separator," Nucl. Instr. and Meth., B70 298 (1992).

16. Davids, B., et al., "Measurement of E2 Transitions in the Coulomb Dissociation of ${ }^{8} \mathrm{~B}$," paper F10, ENAM98.

17. Davids, B., et al., Phys. Rev. Lett. 81 2209-2212 (1998).

18. D' Auria, J. M., et al., "The ISAC Radioactive Beams Facility in Canada: Progress and Plans," paper PG5, ENAM98.

19. Laxdall, R. E., et al., "Status of the ISAC Accelerator for Radioactive Beams," Proceedings of the XIX Interm. Linac Conf., Chicago, IL, August 23-28, 1998, to be published.

20. York, R. C., "The NSCL Coupled Cyclotron Project - Overview and Status," Proceedings of the $15^{\text {th }}$ Interm. Conf. on Cyclotrons and their Applications, Caen, June 14-19, 1998, to be published.

21. "Scientific Opportunities with an Advanced ISOL Facility," November, 1997.

22. Baartman, R., Laxdal, R. E., and Root, L., "Long Range Plan Proposal for an Extension to ISAC," Proceedings of the XIX Interm. Linac Conf., Chicago, IL, August 23-28, 1998, to be published.

23. "Concept for an Advanced Exotic Beam Facility Based on ATLAS, a Working Paper," Physics Division, Argonne National Laboratory, February, 1995.

24. Nolen, J. A., "Accelerator Complex for a Radioactive Ion Beam Facility at ATLAS," Proceedings of the 1995 Particle Accelerator Conference, IEEE 95CH35843, 354-356 (1996).

25. Shepard, K. W., et al., "Niobium Spoke Cavities for a Superconducting Light-ion Linac," Proceedings of the XIX Interm. Linac Conf., Chicago, IL, August 23-28, 1998, to be published.

26. Shepard, K. W., et al., "A Low-charge-state CW RFQ," Proceedings of the XIX Interm. Linac Conf., Chicago, IL August 23-28, 1998, to be published.

27. Nolen, J. A., "A Target Concept for Intense Radioactive Beams in the 132Sn Region," Proceedings of the Third International Conference on Radioactive Nuclear Beams, East Lansing, MI, May 24-27, 1993, Ed. D. J. Morrissey, Editions Frontieres, pp. 111-114.

This work is supported by the DOE under contract W-31-109-ENG-38. 